\title{
Differentiation between Stroke Subtypes and the Causes of Monthly Variations: The Akita Stroke Registry
}

\author{
Manabu Izumi ${ }^{1}$ and Kazuo Suzuki ${ }^{2}$
}

\begin{abstract}
:
Background and purpose It has been established that stroke occurrence is influenced by seasonality. Stroke is divided into three subtypes: cerebral hemorrhage $(\mathrm{CH})$, cerebral infarction $(\mathrm{CI})$, and subarachnoid hemorrhage (SAH). The purpose of this paper was to analyze stroke events by subtype and month, in order to clarify the biggest factors that affect seasonal differences and thereby gain insight into stroke prevention.

Methods Initial stroke events in the Akita Stroke Registry from 1991 to 2010 (58,684 cases; male 30,549, female 28,135) were classified by subtype and the month of onset, and correlations were estimated based on 115 healthy volunteers' monthly mean resting blood pressure (BP) at home and outdoor temperature measured by the Akita Meteorological Observatory in 2001.

Results Systolic BP showed monthly variation in both morning and evening measurements. BP and outdoor temperature showed significant correlations with hemorrhagic stroke events by month $(\mathrm{CH}: \mathrm{r}=0.87, \mathrm{r}=-0.82$; SAH: $r=0.68, r=-0.82$ ). Among the stroke subtypes, seasonal differences were the greatest in $\mathrm{CH}$. Systolic BP was the most important factor for monthly and seasonal variation in stroke events. By comparing monthly $\mathrm{BP}$ variations with $\mathrm{CH}$ incidence throughout the year, we concluded that a decrease in home $\mathrm{BP}$ of $5 \mathrm{mmHg}$ can reduce the risk of $\mathrm{CH}$ by $35 \%$.

Conclusion Our findings suggest that lowering BP would be the best strategy for $\mathrm{CH}$ prevention. Simple daily actions may be affected by cold stress. As physicians, we must strive to help patients lower their BP throughout the year not only with medication but with lifestyle guidance, especially in winter.
\end{abstract}

Key words: monthly variation, blood pressure, stroke epidemiology, intracerebral hemorrhage, stroke registry

(Intern Med Advance Publication)

(DOI: 10.2169/internalmedicine.6146-20)

\section{Background}

Although a large number of studies have reported on stroke prevention measures, stroke is still a leading cause of death and disability around the world. Stroke prevention is considered one of the best strategies for improving public health, on which a great deal of effort has been made. What seems to be lacking, however, is research on the variations in blood pressure on a daily, monthly, and yearly basis under an array of various conditions (1-5).

Stroke occurrence is generally known to increase when the weather gets colder. Blood pressure (BP) is the strongest risk factor for stroke and may be increased by the over- consumption of salt and less physical activity during the cold season (6-8). Stroke is divided into three subtypes: cerebral hemorrhage $(\mathrm{CH})$, cerebral infarction $(\mathrm{CI})$, and subarachnoid hemorrhage (SAH). The magnitude of seasonal variation may differ by subtype, but only a few studies have been carried out on the differences in stroke occurrence by month and by subtype (9). Such an analysis requires the use of large amounts of data. However, there were few reports based on such large amounts of data from a single location. Therefore, the purpose of this paper was to use a large number of stroke events in single location (Akita Prefecture) categorized by subtype and month, to clarify the factors that have the biggest impact on seasonal differences and can be utilized for stroke prevention.

${ }^{1}$ Department of General Medicine, Saiseikai Utsunomiya Hospital, Japan and ${ }^{2}$ Department of Health Preservation, Yuri Kumiai General Hospital, Japan

Received: August 23, 2020; Accepted: February 9, 2021; Advance Publication by J-STAGE: March 29, 2021

Correspondence to Dr. Manabu Izumi, manabu_izumi@saimiya.com 


\section{Methods}

The monthly number of initial stroke events were extracted from the Akita Stroke Registry from 1991 to 2010 $(58,684$ cases; male 30,549 , female 28,135$)$. As described in our previous papers, the Akita Stroke Registry consists of all patients with a stroke event who provided informed consent and were admitted to a hospital, and also includes all stroke events and stroke-related deaths that required immediate hospitalization in all emergency medical facilities in Akita Prefecture (10-13). The study protocol conformed to the ethical guidelines of the 1975 Declaration of Helsinki, and was approved by the ethical committees of the Akita prefectural organization. All stroke events that were referred to a hospital and stroke-related deaths were included in our registry. It was difficult to differentiate between the cases of asymptomatic and symptomatic stroke without reviewing documentation from hospital visits; however, the Japanese health insurance system provides easy access to nationwide data without economic variables, so hidden events in our study population were small enough to be negligible. The WHO MONICA diagnostic criteria for stroke were used in this registry. Based on computed tomography (CT) or magnetic resonance imaging (MRI), strokes were divided into 3 subtypes: cerebral hemorrhage $(\mathrm{CH})$, cerebral infarction (CI), and subarachnoid hemorrhage (SAH).

In 2001, home BP measurements were collected by 115 healthy volunteers living in Akita Prefecture 55 men, mean age 66.5 years; 57 women, mean age 64.6 years). They were recruited from a community health survey in which they reported no subjective symptoms. Those taking medication for hypertension, hyperlipidemia, and diabetes mellitus were excluded from this study. Their morning and night BP were measured on a daily basis for one year. Morning BP was measured within 30 minutes of waking up, before breakfast and taking medicine $(14,15)$. Night BP was measured just before going to bed. Each time, BP was measured only once on the upper arm and recorded.

The number of stroke incidents per month, the average temperature across Akita Prefecture each day in 2001 as recorded by the Akita Meteorological Observatory, and the average home BP among the volunteers were measured and analyzed for correlative relationships using SPSS for Windows (Ver. 12.0; SPSS Japan, Tokyo, Japan). Reductions in risk and $95 \%$ confidence intervals were estimated using the Cox proportional hazards model and applied to the number of patients, not the number of stroke events. The data were adjusted for cohort fixed effects and the fixed model approach was applied with the cohort effects included as dummy variables.

\section{Results}

The mean monthly morning and night $\mathrm{BP}$ and outdoor temperature are shown in Table 1 . Night BP is lower than morning BP across all months, with BP in August being the lowest. The outdoor temperature was also highest in August.

The number, proportions, and confidence intervals of initial stroke events per month, both totaled and divided by subtype, are shown in Table 2. The proportion of total stroke events was the lowest in August, and significantly differed from January, March, and April. Each proportion represents each event for total events per month. Compared with European and American stroke data, the ratio of hemorrhagic stroke $(\mathrm{CH}$ and $\mathrm{SAH})$ in this registry was significantly higher (13). This distribution of stroke subtypes in Japan is similar to that in our previous report (16).

Of the subtypes, only CI seemed to display no seasonal trends. However, $\mathrm{CH}$ and $\mathrm{SAH}$ showed similar behavior, such as a decrease in August and an increase in April. CI was divided into three subtypes: atherosclerotic, cardiac emboli and lacunar. We know each subtype had different risk factors. BP has tendency to elevate with climate getting colder, however, dehydration has a tendency to the contrary. Each risk factor balanced out total seasonal variation of "Ischemic stroke". The correlations between stroke subtypes are shown in Table 3. The correlation index among the stroke subtypes were: $\mathrm{CH}$ and $\mathrm{SAH}, 0.9 ; \mathrm{CH}$ and $\mathrm{CI}, 0.64$; $\mathrm{SAH}$ and CI, 0.63. At this point of view, seasonal behavior of $\mathrm{CH}$ and $\mathrm{SAH}$ were significantly more similar to each other than to CI. In other words, hemorrhagic stroke $(\mathrm{CH}$ and $\mathrm{SAH}$ ) may be more susceptible to seasonal changes than ischemic stroke.

Correlations among BP, the subtypes, and outdoor temperature are shown in Table 4. BP and outdoor temperature showed significant correlations with monthly hemorrhagic stroke events (CH: $r=0.87, r=-0.82$; $\mathrm{SAH}$ : $r=0.68, r=-0.82$, respectively). The correlation between systolic $\mathrm{BP}$ and $\mathrm{CH}$ was within a $1 \%$ significant difference and between systolic $\mathrm{BP}$ and SAH was within 5\% significant difference, but ischemic hemorrhage showed no significance at all. We recognize the similarity between resting $\mathrm{BP}$ and $\mathrm{CH}$ incidence. This similarity could be a clue to the mechanism of seasonal trends in stroke (Figure). By comparing monthly variations in $\mathrm{BP}$ with $\mathrm{CH}$ incidence throughout the year, we estimated that a decrease in home $\mathrm{BP}$ of $5 \mathrm{mmHg}$ could reduce the risk of $\mathrm{CH}$ by $35 \%$.

Outdoor temperature showed a negative correlation with hemorrhagic stroke. The partial correlation coefficient of BP and $\mathrm{CH}$ controlling for temperature was $0.60(\mathrm{p}=0.05)$, and that between outdoor temperature and $\mathrm{CH}$ controlling for $\mathrm{BP}$ was $-0.39(\mathrm{p}=0.23)$. This shows that home resting BP is a stronger risk factor for $\mathrm{CH}$ than cold temperatures in winter.

\section{Discussion}

In this study, we elucidated that monthly trends in total stroke incidence most closely followed the pattern of monthly $\mathrm{CH}$ incidence (Figure). Resting systolic BP at home may be the best predictor for a $\mathrm{CH}$ event (17-18). In comparison with BP measurements taken in a clinical set- 
Table 1. Mean Home BP and outside Temperature by Month.

\begin{tabular}{lccccc}
\hline \multirow{2}{*}{ Month } & \multicolumn{2}{c}{ Morning BP (mmHg) } & \multicolumn{2}{c}{ Evening $\mathrm{BP}(\mathrm{mmHg})$} & \multirow{2}{*}{ Temperature } \\
& Systolic & Diastolic & Systolic & Diastolic & \\
\hline Jan & 132.9 & 78.1 & 125.6 & 72.5 & -0.5 \\
Feb & 132.1 & 78.5 & 124.5 & 73.0 & -0.3 \\
Mar & 133.1 & 77.3 & 125.3 & 71.9 & 2.7 \\
Apr & 132.3 & 77.1 & 125.4 & 72.3 & 8.8 \\
May & 131.9 & 78.6 & 126.0 & 73.9 & 14.1 \\
Jun & 130.3 & 78.2 & 123.7 & 73.1 & 18.5 \\
Jul & 127.8 & 76.3 & 121.3 & 71.3 & 22.6 \\
Aug & 127.4 & 76.2 & 121.1 & 71.2 & 24.0 \\
Sep & 130.9 & 78.0 & 123.7 & 73.0 & 19.4 \\
Oct & 132.7 & 79.2 & 126.0 & 74.1 & 13.1 \\
Nov & 134.5 & 79.1 & 126.7 & 73.7 & 7.3 \\
Dec & 133.9 & 78.7 & 126.4 & 73.4 & 2.3 \\
\hline
\end{tabular}

Temperature: mean outside temperature across Akita Prefecture $\left({ }^{\circ} \mathrm{C}\right)$

Morning BP: mean blood pressure within 1 hour of waking up

Table 2. Monthly Numbers, Proportions, and Confidence Intervals of Stroke Subtypes and Total Stroke from 1991 to 2010.

\begin{tabular}{lcccccccccccc}
\hline & \multicolumn{3}{c}{ Cerebral hemorrhage } & \multicolumn{2}{c}{ Subarachnoid hemorrhage } & \multicolumn{2}{c}{ Cerebral infarction } & \multicolumn{2}{c}{ Total stroke } \\
\cline { 2 - 12 } Month & $\mathrm{N}$ & $\%$ & $95 \% \mathrm{CI}$ & $\mathrm{N}$ & $\%$ & $95 \% \mathrm{CI}$ & $\mathrm{N}$ & $\%$ & $95 \% \mathrm{CI}$ & $\mathrm{N}$ & $\%$ & $95 \% \mathrm{CI}$ \\
\hline Jan & 1,341 & 9 & $7.4-10.3$ & 616 & 9.2 & $6.8-11$ & 3,366 & 9 & $8-9.9$ & 5,323 & 9 & $8.1-9.7$ \\
Feb & 1,295 & 8.7 & $7.3-10.3$ & 586 & 8.8 & $6.6-11$ & 2,833 & 7.7 & $7-8.7$ & 4,714 & 8 & $7.3-8.9$ \\
Mar & 1,451 & 9.8 & $8.1-11.1$ & 634 & 9.5 & $7.1-12$ & 3,330 & 9 & $8-9.8$ & 5,415 & 9.2 & $8.2-9.8$ \\
Apr & 1,332 & 9 & $8.1-11.3$ & 599 & 9 & $7.2-12$ & 3,067 & 8.2 & $8-10$ & 4,998 & 8.5 & $8.3-10$ \\
May & 1,293 & 8.7 & $7.1-10$ & 539 & 8.1 & $5.7-10$ & 3,168 & 8.5 & $7-9.3$ & 5,000 & 8.5 & $7.6-9.1$ \\
Jun & 1,123 & 7.5 & $6.1-9.1$ & 504 & 7.6 & $5.4-10$ & 3,161 & 8.5 & $8-9.6$ & 4,788 & 8.2 & $7.5-9.1$ \\
Jul & 1,022 & 6.9 & $5.2-8.3$ & 517 & 7.8 & $5.4-9.9$ & 3,035 & 8.2 & $7-9$ & 4,574 & 7.8 & $6.9-8.4$ \\
Aug & 960 & 6.5 & $4.8-8$ & 477 & 7.1 & $4.8-9.3$ & 2,942 & 7.9 & $7-8.7$ & 4,379 & 7.5 & $6.6-8.1$ \\
Sep & 1,158 & 7.8 & $6.4-9.4$ & 510 & 7.7 & $5.5-10$ & 2,891 & 7.8 & $7-8.9$ & 4,559 & 7.8 & $7.1-8.7$ \\
Oct & 1,283 & 8.5 & $7-9.9$ & 530 & 8 & $5.6-10$ & 3,102 & 8.4 & $7-9.2$ & 4,915 & 8.4 & $7.5-9$ \\
Nov & 1,296 & 8.7 & $7.3-10.3$ & 554 & 8.3 & $6.1-11$ & 3,080 & 8.3 & $7-9.4$ & 4,930 & 8.4 & $7.7-9.3$ \\
Dec & 1,324 & 8.9 & $7.3-10.2$ & 598 & 8.9 & $6.6-11$ & 3,167 & 8.5 & $7-9.3$ & 5,089 & 8.7 & $7.8-9.3$ \\
\hline Total & 14,878 & 25.3 & & 6,664 & 11.4 & & 37,142 & 63.3 & & 100 \\
\hline
\end{tabular}

$\mathrm{N}$ : Cumulative number of stroke events that occurred in all 20 iterations of a given month across the study period

$\%$ : Percentage of stroke events that occurred in all 20 iterations of a given month across the study period, over total stroke events 95\% CI: $95 \%$ confidence interval

Table 3. Correlations by Stroke Subtype.

\begin{tabular}{lccc}
\hline & SAH & CI & Total stroke \\
\hline $\mathrm{CH}$ & $0.9 * *$ & $0.64 *$ & $0.91 * *$ \\
$\mathrm{SAH}$ & 1 & $0.63 *$ & $0.87 * *$ \\
$\mathrm{CI}$ & $0.63^{*}$ & 1 & $0.75 * *$ \\
\hline$*<5 \% \mathrm{CI}, * * 1 \% \mathrm{CI}$ & &
\end{tabular}

$*<5 \% \mathrm{CI}, * *<1 \% \mathrm{CI}$

$\mathrm{CH}$ : cerebral hemorrhage, SAH: subarachnoid hemorrhage, $\mathrm{CI}$ : cerebral infarction

ting, home BP measurements have the advantage of allowing subjects to take measurements at any time and accumulate substantially more data through daily records $(14,15)$. Further, we used this technique not to evaluate the BP of individuals, but to analyze the trends in $\mathrm{BP}$ for an entire population. $\mathrm{CH}$ onset is directly triggered by high $\mathrm{BP}$, in the form of both resting BP and abrupt increases in BP (ambulatory $\mathrm{BP}$ ), and a perforating artery in the brain rupturing when it overtakes vessel wall stiffness.

Monitoring ambulatory BP can reveal large variations in systolic and diastolic BP throughout the day. However, direct measurement of arterial pressure (in patients undergoing rehabilitation) has revealed the dynamic swings in BP that occur in daily life (18).

Tominaga measured the maximum abrupt changes in systolic BP in hypertensive patients during daily events: an increase of $129 \mathrm{mmHg}$ during urination, $142 \mathrm{mmHg}$ during defecation using a squat toilet (traditionally used in Japan), $120 \mathrm{mmHg}$ during a short medical interview with a doctor, $123 \mathrm{mmHg}$ during a cough, and $104 \mathrm{mmHg}$ during a sneeze 
Table 4. Correlation and Determination by Stroke and BP, Temperature.

\begin{tabular}{lcccccccccccc}
\hline & \multicolumn{4}{c}{ Hemorrhagic subtypes } & \multicolumn{3}{c}{ Ischemic subtype } & \multicolumn{3}{c}{ Total } \\
\cline { 2 - 14 } & \multicolumn{3}{c}{ CH } & \multicolumn{3}{c}{ SAH } & \multicolumn{3}{c}{ CI } & & & \\
& & & D & C & & D & C & D & C & D \\
\hline Morning SBP & 0.87 & $* *$ & 0.76 & 0.68 & $*$ & 0.46 & 0.51 & 0.26 & 0.77 & $* *$ & 0.59 \\
Morning DBP & 0.45 & & 0.2 & 0.15 & & 0.02 & 0.11 & 0.01 & 0.31 & & 0.1 \\
Evening SBP & 0.83 & $* *$ & 0.69 & 0.6 & $*$ & 0.53 & 0.53 & 0.28 & 0.75 & $* *$ & 0.56 \\
Evening DBP & 0.34 & & 0.12 & 0.04 & & 0.02 & 0.07 & 0.05 & 0.24 & 0.06 \\
Temperature & -0.82 & $* *$ & 0.67 & -0.82 & $* *$ & 0.67 & -0.45 & 0.2 & -0.74 & $* *$ & 0.55 \\
\hline
\end{tabular}

$* 5 \% \mathrm{CI}, * * 1 \% \mathrm{CI}$

SBP: systolic blood pressure, DBP: diastolic blood pressure, CH: cerebral hemorrhage, SAH: subarachnoid hemorrhage, CI: cerebral infarction, C: correlation coefficient, D: coefficient of determination

Morning: home BP measurement within 1 hour of waking up

Evening: home BP measurement before going to bed

Temperature: monthly average temperature in Akita

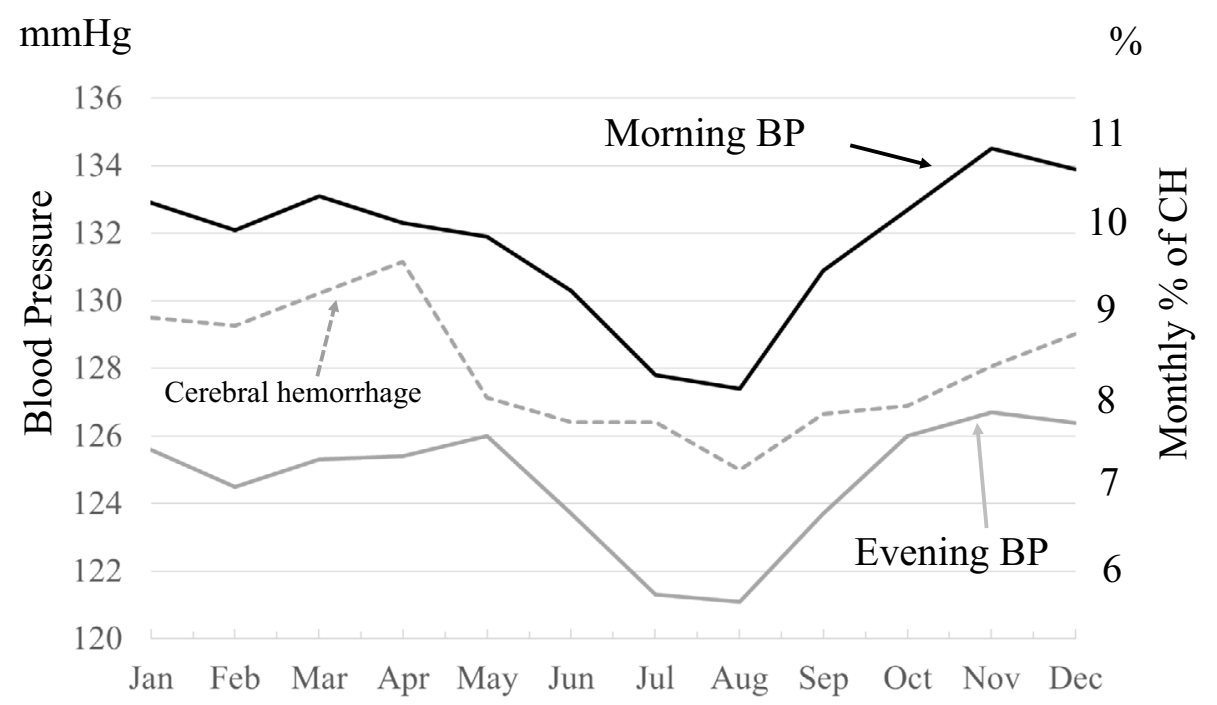

Figure. The monthly distribution of BP and cerebral hemorrhage from 1991 to 2010. The monthly resting BP (morning and evening) was higher in winter than in summer. The ratio of monthly occurrences of cerebral hemorrhage mirrors the trends of BP throughout the year.

Table 5. Abrupt Increases in Systolic BP after Certain Actions (Re-editing from References).

\begin{tabular}{lcccc}
\hline \multicolumn{1}{c}{ Action } & Mean & (Min-Max) & Number & Times \\
\hline Waking up & 23 & $4-62$ & 13 & 14 \\
Defecating & & & & \\
$\quad$ Squat toilet & 77 & $25-142$ & 8 & 11 \\
$\quad$ Western style toilet & 62 & $32-97$ & 4 & 9 \\
Urinating & 32 & $3-129$ & 13 & 47 \\
Climbing stairs & 57 & $24-124$ & 11 & 12 \\
Coughing & 81 & $26-123$ & 4 & 10 \\
Sneezing & 48 & $4-104$ & 4 & 6 \\
Speaking & & & & \\
$\quad$ with doctor & 37 & $12-120$ & 11 & 18 \\
$\quad$ with family & 36 & $4-70$ & 7 & 12 \\
Smoking & 38 & $21-60$ & 3 & 7 \\
Eating & 33 & $3-73$ & 16 & 45 \\
\hline
\end{tabular}

Mean: mean elevation of systolic blood pressure $(\mathrm{mmHg})$

Min: minimum elevation of systolic blood pressure

Max: maximum elevation of systolic blood pressure

Number: number of cases recorded

Times: number of behavior recorded
(Table 5) (18). Real daily BP is made up of these abrupt increases in $\mathrm{BP}$ with resting $\mathrm{BP}$ as a baseline. If a hypertensive patient with a resting $\mathrm{BP}$ of $160 \mathrm{mmHg}$ defecated in a squat toilet, systolic BP could rise to $302 \mathrm{mmHg}$ (Table 5). If a perforating artery in the brain has a limit of $300 \mathrm{mmHg}$, then $\mathrm{CH}$ could occur in an individual when using the toilet. Even if the threshold of $300 \mathrm{mmHg}$ is breached only for an instant, it can be enough to potentially rupture the perforating artery and cause $\mathrm{CH}$.

In the present study, monthly resting $\mathrm{BP}$ in winter was 4 to $6 \mathrm{mmHg}$ higher than in summer. Many previous studies reported the relation between seasonal variation and stroke incidence and mentioned about meteorological factors (6-8). We think that seasonal variation of resting blood pressure is not high, however, it has a sufficiently high value to perforate the cerebrovascular artery, because small seasonal blood pressure variation with additional abrupt elevation of blood pressure among daily performance increase the chances to reach the limitation point of perforation for artery. Cerebral 
Table 6. Linear Regression Analysis between Blood Pressure Variation and Stroke Incidence by Stroke Subtypes.

\begin{tabular}{lcccc}
\hline & $\begin{array}{c}\text { Cerebral } \\
\text { Hemorrhage }\end{array}$ & $\begin{array}{c}\text { Subarachnoid } \\
\text { Hemorrhage }\end{array}$ & $\begin{array}{c}\text { Cerebral } \\
\text { Infarction }\end{array}$ & $\begin{array}{c}\text { Total } \\
\text { Stroke }\end{array}$ \\
\hline number & 14,878 & 6,664 & 37,142 & 58,684 \\
monthly average & $1,239.8$ & 555.3 & $3,095.1$ & $4,890.3$ \\
coefficient of correlation & 0.906 & 0.717 & 0.419 & 0.759 \\
coefficient of determination & 0.821 & 0.515 & 0.176 & 0.576 \\
beta & 58.8 & 16.3 & 30.3 & 105.4 \\
probability & 0.00 & 0.009 & 0.175 & 0.004 \\
beta/monthly average $(\%)$ & 4.74 & 2.93 & 0.98 & 2.16 \\
\hline
\end{tabular}

hemorrhage was triggered with an abrupt elevation of blood pressure, and increased chances of critical situation increase the incidence of $\mathrm{CH}$ in general population in winter. Thus, in this meaning, small seasonal blood variation is not negligible and it is therefore a crucial factor among stroke seasonal variation.

This means the chance of rupturing a perforating artery increases during the cold season and it mirrors the trends of resting systolic BP as shown in Figure.

The correlation coefficient and determination coefficient between morning systolic $\mathrm{BP}$ and the proportion of $\mathrm{CH}$ events per month were 0.87 and 0.76 , respectively. This result suggests that both factors have strong causality. We tried to estimate the proportional reduction in $\mathrm{CH}$ events as a result of lowering BP, as follows.

A linear regression analysis between blood pressure variation and stroke incidence by stroke subtypes are shown in Table 6. A large size population can create this value. $\mathrm{CH}$ and SAH had a significantly high coefficient of correlation (CH: 0.906 and SAH: 0.717, respectively). Amazingly, the value of $\mathrm{CH}$ was extremely high. With this analysis, we could conclude $4.74 \%$ as a value that decreasing $1 \mathrm{mmHg}$ of morning systolic BP could reduce the onset of cerebral hemorrhage events. On the contrary, ischemic stroke (CI) had little correlation with the blood pressure. However, a large number of ischemic stroke events were included in this study population, total stroke had significant correlation with blood pressure variation, because of extremely high correlation between $\mathrm{CH}$ and BP. Large number of study population and monthly data could reveal the impact of BP among stroke subtypes.

BP measured at home is one of the best methods for estimating stroke risk. A quantitative reduction in $\mathrm{CH}$ risk can be achieved by decreasing resting home BP. As physicians, we must strive to help patients lower their BP throughout the year not only with medication but with lifestyle guidance, especially in winter

The authors state that they have no Conflict of Interest (COI).

\section{Acknowledgement}

Akita stroke register staffs, Kyoko Sato and Kimiko Suzuki, done their best effort in controlling stroke data at registration. We thank them for their valuable help.

\section{Statement of Ethics}

The study protocol conformed to the ethical guidelines of the 1975 Declaration of Helsinki, and was approved by the ethical committees of the Akita prefectural organization.

\section{References}

1. Ettehad D, Emdin CA, Kiran A, et al. Blood pressure lowering for prevention of cardiovascular disease and death: a systematic review and meta-analysis. Lancet 387: 957-967, 2016.

2. Rothwell PM, Howard SC, Dolan E, et al. Prognostic significance of visit-to-visit variability, maximum systolic blood pressure, and episodic hypertension. Lancet 375: 895-905, 2010.

3. Pickering G. Hypertension, Causes, Consequences and Management. Churchill Livingstone, London, 1974: 53-58.

4. Chobanian AV, Bakris GL, Black HR, et al. The Seventh Report of the Joint National Committee on Prevention, Detection, Evaluation, and Treatment of High Blood Pressure: the JNC 7 report. JAMA 289: 2560-2572, 2003.

5. Joint National Committee on Prevention Detection, Evaluation, and Treatment of High Blood Pressure. The sixth report of the Joint National Committee on Prevention, Detection, Evaluation, and Treatment of High Blood Pressure. Arch Intern Med 157: 2413-2446, 1997.

6. Salam A, Kamran S, Bibi R, et al. Meteorological Factors and Seasonal Stroke Rates: A Four-year Comprehensive Study. J Stroke Cerebrovasc Dis 28: 2324-2331, 2019.

7. Primatesta P, Poulter NR. Hypertension management and control among English adults aged 65 years and older in 2000 and 2001. J Hypertens 6: 1093-1098, 2004.

8. W C Smith, A J Lee, I K Crombie, et al. Control of blood pressure in Scotland: the rule of halves. BMJ 300: 981-983, 1990.

9. Zheng Y, Wang X, Liu J, et al. A Community-Based Study of the Correlation of Hemorrhagic Stroke Occurrence with Meteorologic Factors. J Stroke Cerebrovasc Dis 25: 2323-2330, 2016.

10. Suzuki K, Izumi M, Sakamoto T, et al. Blood pressure and total cholesterol level are critical risks especially for hemorrhagic stroke in Akita, Japan. Cerebrovasc Dis 31: 100-106, 2011.

11. Izumi M, Suzuki K, Sakamoto T, et al. Advantages and limitations of antihypertensive treatment for stroke risk in a general population: the Akita Stroke Registry. Acta Cardiol 66: 729-735, 2011.

12. Suzuki K, Izumi M. The incidence of hemorrhagic stroke in Japan is twice compared with western countries: the Akita stroke registry. Neurol Sci 36: 155-160, 2015.

13. Suzuki K, Sarti C, Tuomilehto J, et al. Stroke incidence and case fatality in Finland and in Akita, Japan: a comparative study. Neuroepidemiology 13: 236-244, 1994.

14. Asayama K, Ohkubo T, Metoki H, et al. Cardiovascular outcomes 
in the first trial of antihypertensive therapy guided by selfmeasured home blood pressure. Hypertens Res 35: 1102-1110, 2012.

15. Ohkubo T, Kikuya M, Asayama K, et al. Incorporating self-blood pressure measurements at home in the guideline from the Ohasama study. Blood Press Monit 12: 407-409, 2007.

16. Suzuki K. The Characteristics of stroke in Japan. Preventive Gerontology 1: 16-20, 2002.

17. Imai $Y$, Tsuji I, Nagai $K$, et al. Circadian blood pressure variation related to morbidity and mortality from cerebrovascular and cardiovascular diseases. Ann N Y Acad Sci 783: 172-185, 1996.

18. Tominaga S. Recent advances in cardiovascular disease (II). KYOWA KIKAKU, Tokyo, 1981: 25-32.

The Internal Medicine is an Open Access journal distributed under the Creative Commons Attribution-NonCommercial-NoDerivatives 4.0 International License. To view the details of this license, please visit (https://creativecommons.org/licenses/ by-nc-nd/4.0/).

(C) The Japanese Society of Internal Medicine Intern Med Advance Publication 